\title{
REFLEXÕES SOBRE PRECONCEITO - EM BUSCA DE RELAÇÕES MAIS HUMANAS
}

\author{
Mônica Mastrantonio Martins*
}

\begin{abstract}
RESUMO
Esse estudo estabelece princípios que constituem o preconceito, presente tanto na subjetividade como nas relações sociais. O preconceito é concebido como apropriação distorcida da realidade, através da qual projeta-se em outro ser humano, grupo ou sociedade características não aceitas em si mesmo. $O$ preconceito pode estar presente nas ações, linguagem e atitude dos indivíduos. Nas relações pautadas pelo preconceito, outro ser humano é colocado como mero objeto dessa relação, e não como sujeito ativo das relações sociais e constituição da subjetividade. Existem diversos fatores que propiciam o aparecimento e desenvolvimento do preconceito, por exemplo: relações dogmáticas, sem críticas, sem história e sem reflexão entre indivíduos; não identificação dos seres humanos com a humanidade; falta de igualdade de relações sociais e dificuldade de se lidar com fraquezas e imperfeições que são projetadas nos outros. Em
\end{abstract}

* Docente de Psicologia Social - Universidade Estadual de Londrina, mestre em Psicologia Social - PUC/São Paulo. 
um mundo capitalista, baseado na propriedade privada, na alienação e no narcisismo, o preconceito aliena ambos, o sujeito e o objeto do preconceito, em uma relação estática. Exemplos de preconceitos são tão inúmeros e múltiplos quanto a história da humanidade, e variam desde a barbárie do holocausto até piadas e ditos populares que projetam características negativas em grupos minoritários. Nesse sentido, os indivíduos devem procurar compreender o preconceito e suas relações, em especial o psicólogo, que deve ser capaz de desenvolver tais discussões, refletindo e transformando as relações preconceituosas em relações mais humanas, éticas e igualitárias entre os homens.

Palavras-chave: preconceito, atitudes, ética, relações sociais, holocausto.

\begin{abstract}
This study establishes the principles which generate prejudice present both in subjective and actual social relationships.

Prejudice is conceived as a distorted appropriation of reality cohen people project in other people, group or society elements not acceptable in themselves. Prejudice could be present in individuals' actions, language and attitudes. In relationships based in prejudice, the other human being is seen as just an object, and o not as an active subject of the human relation and subjectivity. There are different factors which help in the appearance and development of prejudice in our society, for example: dogmatic relations, with no criticism, no history, and no reflection among individuals, poor identification of human beings with humanity, no equality in the relations, and difficulties in dealing with weakness and imperfections that are projected to the prejudice objects. In a capitalist world, based on private property, alienation and narcissism, prejudice alienates both the subject and object of prejudice in static relation. There are so many examples of prejudice, uncountable as the history of mankind, and vary from the barbarism of holocaust to jokes and proverbs that project the negative characteristics of human kind to
\end{abstract}


minor groups. This way, individuals should try to understand prejudice and its relations, in special the psychologist, should be able to develop such discussions in other to reflect and prejudice relationships into more human, ethical and equal relations among mankind.

Key words: prejudice, attitudes, ethics, social relationship, holocaust.

Parte-se do pressuposto de que preconceito é uma apropriação distorcida da realidade, produzida sócio-historicamente e subjetivamente nas múltiplas e complexas relações entre os homens. O preconceito apresenta-se como construção enviesada do "outro" (nesse caso, outro ser humano, grupo ou sociedade), não baseada em princípios reais, mas na configuração de uma relação na qual sujeito e objeto dessa relação estão dissociados e as determinações do sujeito frente ao objeto são autoritárias, unilaterais e não passíveis de serem transformadas por esse "outro". Nesse tipo de relação, sujeito e objeto encontram-se cindidos, assim como o homem, de suas relações sociais.

No Caderno de luta contra a discriminação produzido pela Secretaria da Educação (1987, p. 10) tem-se a seguinte definição de preconceito: "opinião formada sem conhecimento dos fatos; julgamento feito sem reflexão; idéia antiga a rotineira que não se apóia em provas e argumentos sérios; conceito antecipado; superstição".

Alguns autores, como Ackerman e Jahoda (1969), abordam o preconceito como atitude, ou seja, uma predisposição a esse comportamento que pode ou não ser concretizada, dependendo de uma série de fatores. Segundo ACKERMAN e JAHODA (1969, p. 27), o preconceito é "atitude de hostilidade nas relações interpessoais, dirigida contra um grupo inteiro ou contra indivíduos pertencentes a ele". 
Por outro lado, preconceito não é sinônimo de pré-conceito. Esse último pode ser definido como juízo provisório que pode ser transformado após o contato e conhecimento de outro ser humano ou tema em questão. Assim, o pré-conceito pode se tornar preconceito, quando não há modificação no conceito previamente formado, mesmo após contato com outro grupo ou indivíduo.

O preconceito é abordado nesse trabalho como uma categoria ampla que engloba desde a predisposição à ação até a ação propriamente dita. Exemplos que ilustram o preconceito são inúmeros e podem ser encontrados na linguagem, nas ações e nas atitudes dos sujeitos. Por exemplo, quando a linguagem ou as ações humanas apontam para as seguintes colocações: "A pessoa analfabeta é burra. $\mathrm{O}$ homem é superior à mulher. Preto tem que conhecer o seu lugar. $\mathrm{A}$ pessoa velha só presta para dar trabalho. Índio é preguiçoso e não gosta de trabalhar. Na favela só mora marginal. Melhor morrer do que ficar deficiente. Homossexual é safado ou doente. Quem não acredita em Deus não tem alma." Entre tantas colocações, percebe-se nesses ditados populares o desprezo e a hostilidade frente ao outro ser humano, objeto do preconceito.

O preconceito é constituído nas meditações da subjetividade e das relações sociais e, portanto, tanto o estudo desse tema como sua transformação são extensos, complexos e envolvem uma variedade de fatores que devem ser analisados, mesmo nas manifestações mais subjetivas e específicas de preconceito. Desse modo, o preconceito é produto e produtor das intermediações entre subjetividade e sociedade.

Portanto, estudar e pesquisar o preconceito é tarefa árdua, mas urgente. Árdua, porque quando se aborda o preconceito, também deve-se tratar de como os seres humanos apropriam-se da realidade e agem frente a ela. Urgente, porque o preconceito é uma construção deturpada da realidade, presente nas ações e emoções do cotidiano. Nesse sentido, a Psicologia e, em especial a Psicologia 
Social, abrem possibilidades para compreensão do preconceito, ao buscarem compreender a subjetividade produzida e produtora das relações sociais.

Nos estudos de Crochík (1995 e 1996), o preconceito é apontado como desvio da razão (também chamado de "má consciência" ou "irracionalidade"). Nesse caso, o preconceito também aparece como produto da irracionalidade da sociedade atual, visto que esta produz indivíduos dissociados de si mesmos e que não se identificam com diferentes seres humanos. Se não há identificação do sujeito com os demais seres humanos, esses tornam-se alvos fáceis do preconceito pela projeção de fatores negativos sobre eles. De acordo com Crochík (1996, p. 59): "À medida que a contradição entre sociedade e indivíduo se amplia, a contradição interna do indivíduo também aumenta". Isso propicia que o preconceito torne-se dominante nas intermediações das relações sociais e subjetividade.

Dessa forma, o preconceito pode ameaçar a autoconservação humana, por não garantir a racionalidade presente em relações sociais mais humanas; mas incentivar a competição, rivalidade, oposição e combate dos seres humanos entre si.

Relações sociais que são unilaterais, imediatistas e autoritárias também estão presentes no preconceito. Esse aspecto também é conseqüência da falta de reflexão sobre si mesmo e sobre os outros, de um pensar rígido sobre si mesmo de forma positiva, e de forma negativa do "outro".

Muitas vezes, o preconceito é uma forma de defesa diante do "outro", que é visto como uma ameaça ao sujeito. É o falseamento da realidade através de uma relação determinista, unilateral e imutável imposta pelo sujeito. Nesse caso, ocorre um empobrecimento da multiplicidade das relações humanas, pois esse "outro" é impossibilitado de se diferenciar ou transformar tal preconceito. 
Diante de uma relação preconceituosa, tanto quem manifesta preconceito quanto quem sofre preconceito torna-se espectador das relações sociais, por seguir padrões sociais impostos sem reflexão.

Para Crochík (1996, p. 44) "A tipificação dos indivíduos, na realidade, não é fruto das categorias científicas, mas da própria transformação social: os indivíduos tornaram-se propícios a serem tipificados". Ou seja, a tipificação de comportamentos e atitudes pode ser preconceituosa quando impossibilitar a transformação das mesmas. A tipificação preconceituosa dos sujeitos está presente em nossa sociedade, quando indivíduos são tipificados de maneira estanque, descontextualizada e a-histórica. Ela pode estar presente na ciência ou mesmo na Psicologia: mas não se restringe a essas. O principal problema nesse caso é que tais tipificações restringem multiplicidade e complexidade humanas, alienando o homem da possibilidade de existir fora dessas tipificações e classificações. Um exemplo disso são as tentativas de agrupamento de casais realizadas por diversas agências matrimoniais que cadastram e formam pares através de programas de computador. Tais serviços apontam o tipo ideal que se procura. Mas relações humanas e conjugais são muito mais complexas do que tipos encontrados nessas agências, demonstrando que tentativas de tipificar e classificar os seres humanos são muitas vezes inúteis e não produzem os resultados desejados.

Quando Adorno e Horkheimer (1985, p. 205) dizem que "A classificação é a condição do conhecimento, não o próprio conhecimento, e o conhecimento por sua vez destrói a classificação", eles apontam que o sujeito do conhecimento constrói classificações para a compreensão de um determinado objeto, mas não deve ficar preso a essas classificações, padronizações e tipificações. $O$ indivíduo só pode existir enquanto sujeito de si mesmo e de suas relações sociais quando construir uma sociedade que não tipifique, padronize e classifique o ser humano em categorias fixas e rígidas, sem a possibilidade de transformação das mesmas. 
Muitas vezes, na própria construção da linguagem, existem conceitos e termos que são embutidos de preconceito, como é o caso do termo deficientes. Como a própria palavra já diz, essas pessoas são apontadas como sendo deficientes em algo ou alguma coisa. $\mathrm{O}$ preconceito está presente na linguagem quando ocorre a generalização de características que são particulares de um determinado grupo, pessoa ou objeto ou quando não há flexibilidade e contextualização dos termos e conceitos.

Isto quer dizer que o preconceito está pautado por classificações distorcidas e errôneas frente à realidade, que são também a-históricas, deterministas e autoritárias de uns frente a outros. Por exemplo, ditados e piadas populares sobre diversas minorias colocam o "outro" como objeto de preconceito quando relatam que "preto correndo é ladrão, e parado é vagabundo".

Carone (1995, p. 111) também aborda essa questão quando discute a classificação dos distúrbios de personalidade do sujeito preconceituoso, apontando que se deve ter cuidado na classificação desse, principalmente quando dissociada da sociedade propiciadora do preconceito:

\begin{abstract}
Os autores que admitem a existência de distúrbios de personalidade no sujeito (autoritário) identificavam fascismo com (desajustamento social) e até (misantropia) e a psicoterapia como instrumento de readaptação do autoritário. Será que o fascista é realmente um desajustado numa sociedade ou atmosfera cultural que legitima (quando não legaliza) a segregação racial das minorias étnicas?
\end{abstract}

Logo, a discussão do preconceito, segundo moldes da patologia e do distúrbio emocional, postula o preconceito como forma hegemônica de adaptação à sociedade. Preconceito é ação imediata, sem reflexão, que expressa a fragilidade do indivíduo frente às suas próprias experiências, demarca defesas e paralisias na relação com o outro e reproduz adaptações frente ao preconceito dominante na 
sociedade. Nessa sociedade, é freqüente a incorporação do homem como objeto de suas relações sociais e não como sujeito das mesmas, o que facilita ainda mais a disseminação, adaptação e banalização do preconceito.

Mesmo que nas afirmações preconceituosas possam haver elementos verdadeiros com relação ao "outro", esse continua sendo objeto do preconceito porque seus aspectos subjetivos, dinâmicos e históricos não são levados em consideração. Desse modo, o que é psicossocial torna-se natural e imutável, pelo fato de não se considerar possibilidades de transformação desses aspectos.

Ocorre assim, a dissociação de determinadas características com certos grupos ou pessoas. Características essas que não são próprias dos mesmos, mas, muitas vezes, elementos que o sujeito não aceita em si mesmo e projeta no "outro".

Então, é fundamental a reflexão sobre como são estabelecidas e construídas as relações psicossociais, para análise de como essas relações estão sendo preconceituosas ou éticas. A ética pode ser encontrada nas relações sociais se essas expressam aspectos democráticos e de igualdade; ou seja, quando sujeito e objeto participam na construção da realidade e da sociedade.

Com o preconceito, existe uma relação de dominação de um ser humano frente a "outro", pela imposição de características distorcidas da realidade. Nesse caso, sujeito e objeto permanecem prisioneiros de uma situação que não possibilita reflexões, transformações ou construções de relações mais igualitárias.

Como já mencionado, a ciência, conhecimento construído pelo homem, não é neutra e, como tal, pode ser fruto do preconceito ou estar pautada por elementos preconceituosos. Sendo assim, até mesmo a própria Psicologia não está necessariamente isenta de preconceito. Nietzsche (1993, p. 29) já nos adverte quanto aos perigos de uma Psicologia pautada no preconceito: 
Toda a psicologia, até o momento, tem estado presa a preconceitos e temores morais: não ousou descer às profundezas. Compreendê-la como morfologia e teoria da evolução da vontade de poder, tal como faço - isto é que ninguém tocou sequer em pensamento: na medida em que é permitido ver, no que até agora foi escrito, um sintoma do que até aqui foi silenciado. A força dos preconceitos morais penetrou profundamente no mundo mais espiritual, aparentemente mais frio e mais livre de pressupostos - de maneira inevitavelmente nociva inibidora, ofuscante, deturpadora.

Isto significa que psicólogos também devem refletir criticamente sobre relações entre sujeito e objeto, com o cuidado de não reproduzir o preconceito através de concepções errôneas diante da realidade do "outro", mas garantir que esse "outro" possa se expressar, quer seja em estudos, pesquisas ou prática profissional. Ou seja, ninguém é imune ao preconceito.

Enquanto produção psicossocial, o preconceito está relacionado com uma cultura que usufrui desse para obtenção de lucros e ganhos. É o caso da sociedade pautada na propriedade privada, cuja subjetividade é fundamentalmente construída através dessa propriedade, resultando em um empobrecimento das relações sociais. Conseqüentemente, a identificação dos seres humanos com a humanidade fica em segundo plano, e busca-se a posse e identificação dos sujeitos com objetos da propriedade. A competição diante da propriedade privada pode facilitar a dissociação entre sujeito e objeto, principalmente se as relações entre os homens tornam-se apenas meios para o alcance de outros fins.

Além desses aspectos, a sociedade atual muitas vezes dificulta reflexões, críticas e questionamentos sobre si própria. Tais fatos não produzem apenas a alienação dos seres humanos, mas também condições propícias ao aparecimento do preconceito. Uma sociedade pautada no preconceito é uma sociedade sem reflexão e sem razão. Kant (1992, p. 13) aponta isso ao declarar: 
Mas agora ouço gritar de todos os lados: não raciocines! Diz o oficial: não raciocines mas faz exercícios! Diz o funcionário de Finanças: não raciocines, acredita! (Apenas um único senhor no mundo diz: raciocinai tanto quanto quiserdes e sobre o que quiserdes, mas obedecei!). Por toda parte se depara com a restrição da liberdade.

Adorno (1986, p. 34) relata que a raiva e a revolta estão presentes quando as pessoas sentem-se enclausuradas na sociedade. A irracionalidade disso repousa no fato de que o ser humano é constituído nas suas relações sociais e facilmente se perde quando se distancia das mesmas:

Pode-se falar de uma claustrofobia da humanidade no mundo
administrado, uma sensação de clausura em um contexto mais e mais
socializado, densamente estruturado. Quanto mais apertada a rede, mais
quer-se sair dela, muito embora sua própria estreiteza o impeça. Isso
aumenta a raiva contra a civilização. A revolta contra ela é brutal e
irracional.

No entanto, apesar de o preconceito não ser algo exclusivo ou recente na sociedade atual, tem apresentado dimensões e características amplamente assustadoras nesse século. Para Hobsbawn (1995, p. 122) "o fim do século XIX introduziu a xenofobia de massa, da qual o racismo - a proteção da cepa local pura contra a contaminação, e até mesmo a submersão, pelas hordas invasoras subumanas - tornou-se expressão comum".

Adorno em seu texto "Educação após Auschwitz" (1986, p. 42) descreve a frieza e a indiferença com que os homens vivem suas relações na atualidade. É comum indivíduos encontrarem dificuldades para amar, entregar-se, ou parar de se defender diante dos outros em uma sociedade que incentiva o narcisismo, o culto do "eu" e de relações individualistas, nas quais o "outro" só aparece como elemento figurativo de si próprio. 
Segundo Lasch (1987, p. 47), a cultura do narcisismo é estratégia de sobrevivência frente às adversidades enfrentadas hoje:

\begin{abstract}
A apatia seletiva, o descompromisso emocional frente aos outros, a renúncia ao passado e ao futuro, a determinação de viver um dia de cada vez - tais técnicas de autogestão emocional, necessariamente levadas ao extremo em condições extremas, passaram a configurar, em formas mais moderadas, a vida das pessoas comuns em condições normais de uma sociedade burocrática.
\end{abstract}

Enfim, uma sociedade que produz e reproduz relações preconceituosas é a mesma sociedade que produz indivíduos pouco críticos, que facilmente aceitam e reproduzem seus dogmas. A falta de questionamentos e a construção de discursos que justificam o próprio preconceito são produtos da "má consciência". A "má consciência" é a consciência deformada por um saber aleatório e deturpado diante do outro, da realidade e de si próprio.

O problema maior do preconceito aparece quando se busca a eliminação do "outro", objeto de projeção dos aspectos negativos não aceitos em si próprio, como é o caso no holocausto e nos grupos de extermínio. Tais barbáries incompreensíveis em nossa consciência, por mais que se busque explicações para tais fatos. Ao abordar a questão do nazismo e do holocausto, Kershaw (apud Hobdbawn, 1995, p. 13) coloca:

No nazismo, temos um fenômeno difícil de submeter-se à análise racional. Sob um líder que falava em tom apocalíptico de poder ou destruição mundiais, e um regime fundado numa ideologia absolutamente repulsiva de ódio racial, um dos países mais cultural e economicamente avançados da Europa planejou a guerra, lançou uma conflagração mundial que matou cerca de 50 milhões de pessoas, e perpetuou atrocidades - culminando no assassinato mecanizado em massa de milhões de judeus - de uma natureza e escala que desafiam a imaginação. Diante de Auschwitz, os poderes de explicação do historiador parecem deveras insignificantes. 
Embora preconceito e ideologia não sejam sinônimos, podem estar relacionados. Ideologia é um falseamento da realidade que justifica contradições existentes na sociedade e explica o sofrimento diante da realidade. Preconceito é o falseamento e deturpação da realidade pela atribuição de elementos conflitantes ao "outro". É a projeção de aspectos negativos frente a um objeto quando não se consegue lidar com esses aspectos em si próprio, atribuindo tal fragilidade ao "outro". Preconceito pode ser correlacionado com ideologia quando justifica contradições e diferenças sociais existentes segundo classificações e tipificações de raça, cor, religião, sexo, entre outras.

A opinião pública também pode apresentar elementos preconceituosos, mas não deve ser confundida com preconceito. Ela pode colaborar na construção do mesmo quando globaliza aspectos particulares, levando fatos da esfera privada para a pública de modo aleatório, dogmático e descontextualizado. Para Adorno (1969, p. 141), é necessário cuidado no enunciamento e julgamento das opiniões:

Em general, tener uma opinión, enunciaria, es algo que se constituye en cierta medida contra la experiencia y tiende a la ilusión, mientras que por el otro lado solo tiene razón el que es capaz de juzgar: aquí radica quizás la contradicció más profunda e insuperable en la opinión.

Opiniões e dogmas podem, a princípio, facilitar o posicionamento do homem diante da sociedade, mas dificultam reflexões, transformações do preconceito e a formação de indivíduos críticos. Segundo Marcuse (1972, p. 120): "O homem, para conduzir-se, não tem necessidade de problemas, e sim de crenças. Seu berço deve ser rodeado de dogmas; e, quando sua razão desperta, é preciso que ele encontre todas as suas opiniões prontas, pelo menos sobre tudo que diz respeito à sua conduta". O resultado disso são indivíduos frágeis, menos autônomos 
e menos racionais e sobram poucos parâmetros para uma crítica dos preconceitos presentes nessas opiniões.

A sociedade atual também contribui para a constituição do preconceito ao naturalizar determinadas características como integrantes exclusivas de uma determinada cultura, raça ou religião. As falas populares apresentam exemplos como: Japoneses são um povo trabalhador. Católicos são tradicionalistas. Imigrantes aumentam o desemprego.

A dificuldade em lidar com a diversidade também está presente nessa sociedade e facilita o desenvolvimento do preconceito. Diferentes culturas, raças e religiões são apresentadas como elementos anônimos, desconhecidos e violentos, e, muitas vezes, são elementos negados em si próprios e projetados no "outro". A competitividade dessa sociedade favorece relações hostis e de anulação do outro ser humano, principalmente quando a supremacia de um sobre o outro significa a própria sobrevivência. Então talvez, seja o mais cruel exemplo do que é o preconceito e do que se faz em nome dele.

Nesse caso, fatores negativos que são difíceis de se aceitar em si mesmo são mais facilmente projetados no "outro", representante das dificuldades e fragilidades dos seres humanos.

As perseguições exemplificam o quanto o preconceito abarca elementos destrutivos em nossa sociedade e o quanto esse está presente nas mortes diárias dos pobres, meninos de rua, andarilhos, sem-terra, judeus, presos, ladrões, aidéticos, idosos, entre outros; desqualificados dos aspectos humanos e apresentados como objetos que os homens não assumem em si mesmos. Enfim, Crochík (1995, p. 43) aponta que o preconceito funciona como mecanismo de defesa diante das relações sociais, impedindo que o sujeito entre em contato com o "outro", representante de conteúdos negados em si mesmo.

Adorno (1986, p. 37) explicita elementos que devem ser resgatados na construção de uma sociedade livre do preconceito: "A única verdadeira 
força contra o princípio de Auschwitz seria a autonomia, ... a força para reflexão, para a autodeterminação, para a não-participação." Contudo, os espaços e situações que proporcionam relações mais calcadas no esclarecimento, na ética e no respeito ao "outro" pelo que ele é, e não pelo que se quer que ele seja, são raros.

Diante desses elementos, relações humanas sem preconceito são raras, porém não são impossíveis de serem encontradas. $\mathrm{Na}$ maior parte delas, o preconceito está presente em maior ou menos grau e sob diferentes formas. Um exemplo é o caso do indivíduo que conta piadas sobre portugueses com conteúdos negativos e pejorativos, mas que jamais seria capaz de matar um português pelo fato de ele ser português. Por outro lado, existe aquele indivíduo que não expressa verbalmente elementos negativos sobre judeus, mas que fomenta ódio e hostilidade perante fato de seu patrão ser judeu e ter sucesso nos negócios. Um caso mais extremo seria o do indivíduo, que talvez nem tenha consciência das razões de sua hostilidade frente aos negros, mas é capaz de matá-los sem culpa.

Hobsbawn (1995, p. 123) também descreve a hostilidade projetada sobre os judeus, diante das conquistas obtidas por esse grupo:

Os judeus estavam presentes em quase todo o lugar e podiam simbolizar com facilidade tudo o que haviam de mais odioso em um mundo injusto, inclusive seu compromisso com as idéias do iluminismo e da Revolução Francesa que os tinham emancipado e, ao fazê-lo, os haviam tornado mais visíveis. Eles podiam servir como símbolos do odiado capitalista/financista; do agitador revolucionário; da corrosiva influência dos intelectuais sem raízes e dos novos meios de comunicação, da competição - como poderia ela ser outra coisa que não 'injusta'? - que lhes dava uma fatia desproporcional dos empregos em certas profissões que exigiam educação; e do estrangeiro e forasteiro como tal.

Isso nos leva a pensar que o preconceito tem se tornado um modo dominante de deturpação da realidade e do "outro" na sociedade atual, pelo fato de atribuir a esse "outro" características e classificações 
que são subjetivas e aleatórias. Isso configura relações pautadas pelo medo, incerteza, indiferença, frieza e hostilidade, principalmente quando o "outro" não é mais visto como ser humano com quem se identifica e constrói a realidade. Aspectos como esses também estavam presentes na sociedade de Hitler e não estão distantes da atualidade. Hobsbawn (1995, p. 134) cita que o imperativo de Hitler era "honra significa obediência cega", o que refletia "uma sociedade hierárquica rígida, total dedicação do indivíduo à nação e seu imperador e absoluta rejeição dos ideais iluministas: liberdade, igualdade e fraternidade."

Judeus e inúmeros grupos foram mortos, perseguidos e tratados como não-humanos. $O$ filme $A$ lista de Schindler exemplifica tal colocação, quando um soldado alemão vai exterminar judeus, mas hesita no momento de puxar o gatilho da arma e ouve do oficial superior, a seguinte frase: "Não precisa pensar, é só apertar o gatilho, eles não sentem, eles não são como nós, eles não são gente."

$\mathrm{Na}$ história da humanidade não faltam exemplos de preconceito, irracionalidade, falta de autonomia, de igualdade e de ética nas relações humanas. $O$ fato crucial talvez seja que construímos uma sociedade na qual os homens não se identificam entre si e buscam mais eliminar diferenças do que respeitá-las. Sem tal identificação, a humanidade torna-se impossível e a barbárie, altamente provável.

Quando o ser humano torna-se meio para atingir fins como poder, capital, status e outros, não é difícil crianças serem seqüestradas e assassinadas para delas tirarem seus órgãos. A colocação pertinente é: que vida é essa que legitima a vida de alguns, enquanto postula a morte de outros? Uma vida que não tem sentido em si mesma, já não tem sentido algum e já não é mais vida.

Nada, porém, justifica uma aceitação passiva dessas deturpações entre sujeito e objeto, características do preconceito. Aceitá-lo como parte integrante e natural da sociedade e dos indivíduos 
é transformar uma construção psicossocial em dogma e contribuir para a efetivação do preconceito e a desumanização do homem. Portanto, "a única coisa que nos resta é a revolta contra a condição humana que não escolhemos", alerta Kundera (1995, p. 103).

Para tal empreendimento "nada mais se exige do que a liberdade, e claro está mais inofensiva entre tudo o que se pode chamar liberdade, a saber, a de fazer um uso público da razão, da sua razão em todos os elementos", diz Kant (1992, p. 13). A razão auto-reflexiva pode possibilitar a construção de uma sociedade na qual os homens possam se identificar e ser identificados como seres humanos.

Crochík (1995, p. 18) também compartilha da colocação de Kant ao apontar que "a experiência e a reflexão são as bases da constituição do indivíduo na sua relação com a cultura, a sua ausência caracteriza o preconceito".

Uma ação não preconceituosa só será possível quando cada indivíduo for visto como um ser em particular e, ao mesmo tempo, representante do gênero humano, pois "só é solidário aquele que se permite ver como o outro, ou seja, identificar-se com este outro sem anular ou ocultar esta identificação" (Crochík, 1995, p. 106).

Por último, refletir sobre a questão do preconceito é pensar na dificuldade de assumir a própria desumanização e tentar transformá-la. Mas isso requer não só humildade na aceitação de que não se constrói o mundo sozinho, como também ética para respeitar o "outro" como ele é e não como se gostaria que ele fosse; política para não aprisionar o "outro" pelo poder, autoritarismo ou escravidão; psicologia para compreendê-lo como sujeito único, assim como todos somos seres particulares; e sabedoria para analisar criticamente as relações atuais e construir uma sociedade na qual a vida valha ser vivida.

Talvez algo parecido com o que o escritor africano Roland Tombekai Dempster (1978, p. 64) descreve em seu poema: 
Eu não sou você mas você não me dará uma chance, não deixará eu ser eu.

Se eu fosse você mas você sabe Eu não sou você, ainda assim você não deixará eu ser eu. Você atrapalha, interfere nos meus negócios como se eles fossem seus e você fosse eu. Você é injusto, e não é sábio tolo em pensar, que eu possa falar, atuar e pensar como você.

Deus me fez Ele fez você Pelo amor de Deus Deixe-me ser eu mesmo. 


\section{REFERÊNCIAS BIBLIOGRÁFICAS}

ACKERMAN, N. W.; JAHODA, M. Distúrbios emocionais e anti-semitismo. São Paulo: Perspectiva, 1969.

ADORNO, T. W. Educação após Auschwitz. In: Sociologia. São Paulo: Ática, 1986.

Ávila Editores, 1969.

Opinión, loucura, sociedad. In: Intervenciones. Caracas: Monte . HORKHEIMER, M. Dialética do esclarecimento. Rio de Janeiro: Jorge Zahar, 1985.

CARONE, Iray. Teoria crítica e psicologia social: o impacto do Instituto de Pesquisa Social na investigação psicossocial. In: Psicologia e política. São Paulo: Cortez, 1995.

CROCHÍK, José Leon. Preconceito: indivíduo e cultura. São Paulo: Robe Editorial, 1995.

Notas sobre a psicologia de T. W. Adorno. In: Psicologia \& Sociedade, v. 8, n. 1, jan./jun. 1996. Revista da Associação Brasileira de Psicologia Social - ABRAPSO.

HOSBAWN, Eric. A era dos extremos: o breve século XX - 1914-1991. São Paulo: Companhia das Letras, 1995.

KANT, Imanuel. Resposta à pergunta: o que é lluminismo? In: A paz perpétua e outros opúsculos. Lisboa: 70, 1992.

KUNDERA, Milan. A lentidão. Rio de Janeiro: Nova Fronteira, 1995.

LASCH, Christopher. O mínimo eu: sobrevivência psíquica em tempos difíceis. São Paulo: Brasiliense, 1987.

MARCUSE, Hebert. Estudo sobre a autoridade e família. In: Idéias sobre uma teoria crítica da sociedade. Rio de Janeiro: Zahar, 1972.

NIETZSCHE, F. Além do bem e do mal: prelúdio a uma filosofia do futuro. São Paulo: Companhia das Letras, 1993. 
SECRETARIA DO ESTADO DA EDUCAÇÃO - ASSESSORIA TÉCNICA DE PLANEJAMENTO E CONTROLE EDUCACIONAL. A escola na luta contra a discriminação. São Paulo: Fundação para Desenvolvimento da Educação, 1987.

SWAN, Michael. Spectrum. Cambridge: Cambridge University Press, 1978. 